\title{
ENDOVENOUS LASER ABLATION OF INCOMPETENT CALF PERFORATING VEINS DOES NOT PREVENT RECURRENCE OF VENOUS ULCERS IN PATIENTS WITH POST-THROMBOTIC SYNDROME
}

Igor Zolotukhin, Evgeny Seliverstov, Karina Khabazova, Evgeny An, Igor Lebedev

Pirogov Russian National Research Medical University, Moscow, Russia

\begin{abstract}
Aim of the study was to assess efficacy of endovenous laser ablation of incompetent calf perforators in patients with post-thrombotic syndrome in preventing recurrence of venous leg ulcers.

Material and methods: We conducted a single-centre prospective randomized study. Patients with healed venous ulcers were randomly assigned either to endovenous laser ablation of incompetent calf perforators together with compression therapy $(n=31)$, or to compression alone $(n=32)$. We used a $940 \mathrm{~nm}$ laser system and under sonographic control ablated all incompetent perforators in the area of healed ulcers. The primary endpoint of the study was the rate of ulcer recurrence within one year of follow-up. The technical success of laser ablation was assessed by duplex ultrasound 3-5 days and 1 year after the procedure.

Results: Puncture and laser ablation of all perforators intended to treat was successful, irrespective of their location and diameter. There were no intraoperative and postoperative complications. The occlusion rate of perforators after 3-5 days was $76.9 \%$. After one year only 17 perforators (18.7\%) were still occluded. Venous ulcers recurred in 10 patients (32\%) managed with laser ablation and in 11 patients (34\%) using compression alone $(p=0.859)$. After one year in both groups of patients, the mean Venous Clinical Severity Score did not change.

Conclusions: Endovenous laser ablation of incompetent perforating veins did not reduce the recurrence of venous ulcers in patients with post-thrombotic syndrome. The technical success of this procedure was low and the majority of incompetent perforating veins reopened within a year.
\end{abstract}

Key words: laser ablation, calf perforators, venous ulcer, post-thrombotic syndrome.

\author{
ORIGINAL PAPER \\ Phlebological Review 2015; 23, 2: 54-59 \\ DOl: $10.5114 /$ pr.2015.54036
}

Submitted: 12.02.2015

Accepted: 10.07.2015

\section{ADDRESS FOR CORRESPONDENCE}

Evgeny Seliverstov

Russian National Research Medical University named after N.I. Pirogov

Ostrovityanova 1

117997 Moscow

Russian Federation

e-mail: flebolog@rambler.ru

\section{INTRODUCTION}

Chronic venous disease (CVD) is one of the most common vascular pathologies. As it has been shown by epidemiological studies, venous symptoms and signs can be found in $49 \%$ of adults in Europe [1]. Post-thrombotic syndrome (PTS) is one of the forms of chronic venous disease. Post-thrombotic syndrome develops as a result of deep vein thrombosis (DVT). Prevalence of PTS in the adult population is still unknown, because epidemiological studies on this issue have not yet been conducted. Previously published studies have focused mainly on CVD, without distinguishing between primary and post-thrombotic disease. The annual incidence of PTS may be estimated indirectly, taking into account the annual incidence of DVT, which has been reported to be at a level of $124-160$ per 100,000 people per year
$[2,3]$. Considering the fact that $30-50 \%$ of DVT patients will later develop PTS [4], one can approximate the incidence of PTS. In about $10-20 \%$ of the patients, a severe PTS develops, which manifests with permanent limb oedema, trophic changes of the skin and leg ulcers $[5,6]$. Post-thrombotic venous ulcers are usually hard to heal and their recurrence rate is extremely high (24-69\% after 12 months) [7-10]. Since the introduction of Linton's operation (dissection of incompetent calf perforators) in 1938, the opinion that reflux in perforating veins has an important influence on development of leg ulcers has been widely accepted by surgeons. In addition to open ligation of incompetent perforators, a number of alternative methods aimed at accelerating ulcers healing and preventing their recurrence have been suggested, including subfascial endoscopic dissection and - more recently - endovenous thermal ablation, using either laser or 
radiofrequency systems. Thermal ablation seems to be a very promising technique and some studies have shown significantly lower rates of ulcer recurrence after such a treatment $[11,12]$. However, these studies have primarily examined clinical outcomes of patients with superficial venous reflux, who in general present with better results of the treatment than patients with PTS. The aim of our study was to assess efficacy of endovenous laser ablation of incompetent calf perforators in PTS patients in preventing recurrence of venous leg ulcers.

\section{MATERIAL AND METHODS}

\section{Study design}

We conducted a single-centre randomized controlled study in two groups of C5 patients with PTS.

Inclusion criteria were as follows:

- any sex,

- age 18-75,

- C5 class of CVD (healed venous ulcer),

- PTS confirmed by sonographic examination,

- incompetence of perforating veins of the calf confirmed by sonographic examination,

- presence of incompetent perforators in the area of the healed ulcer revealed by sonographic examination,

- informed consent.

Exclusion criteria were as follows:

- more than 8 weeks after healing of the ulcer,

- active ulcer on the day of assessment,

- inability to regularly wear compression stockings,

- possible problems with regular contact with the patient during follow-up,

- unwillingness to sign the informed consent.

A total of 98 patients with C6 class and documented PTS were assessed from January 2012 to October 2013.
All of them received conservative treatment for active venous ulcers in the specialist outpatient venous ulcer clinic of our hospital. The presence of PTS was confirmed by duplex ultrasound in all patients. After the ulcers were healed, patients were referred to our research team. From this group, 35 patients were excluded: 6 had open ulcers, 12 were older than 75 years, and 17 were non-compliant with compression therapy or refused to sign informed consent (Fig. 1). Therefore, we included 63 patients with PTS and C5 class of CVD. All of them were clinically examined and their Venous Clinical Severity Score (VCSS) was assessed. Duplex ultrasound examinations were performed to confirm the presence of PTS and to assess calf perforators. All patients signed the consent after having received full information about the study. Then they were randomly assigned either to endovenous laser ablation of calf perforators with a subsequent use of $30-40 \mathrm{~mm} \mathrm{Hg}$ compression stockings (study group, $n=31$ ), or to the same type of compression alone (control group, $n=32$ ). Baseline characteristics of patients from both groups are presented in Table 1 . There were no statistically significant differences between the study and control groups regarding patients' sex, age, duration of PTS, total number of incompetent perforating veins and percentage of perforating veins wider than $3.5 \mathrm{~mm}$.

The study was approved by the Ethical Committee of the Pirogov Russian National Research Medical University.

\section{Assessment of flow in the calf perforating veins}

To evaluate the competence of the perforators, patients were examined by duplex ultrasound (Mindray M5, linear array 5-10 MHz, Shenzhen Mindray Bio-Medical Electronics Co., Ltd, China) in the standing position with

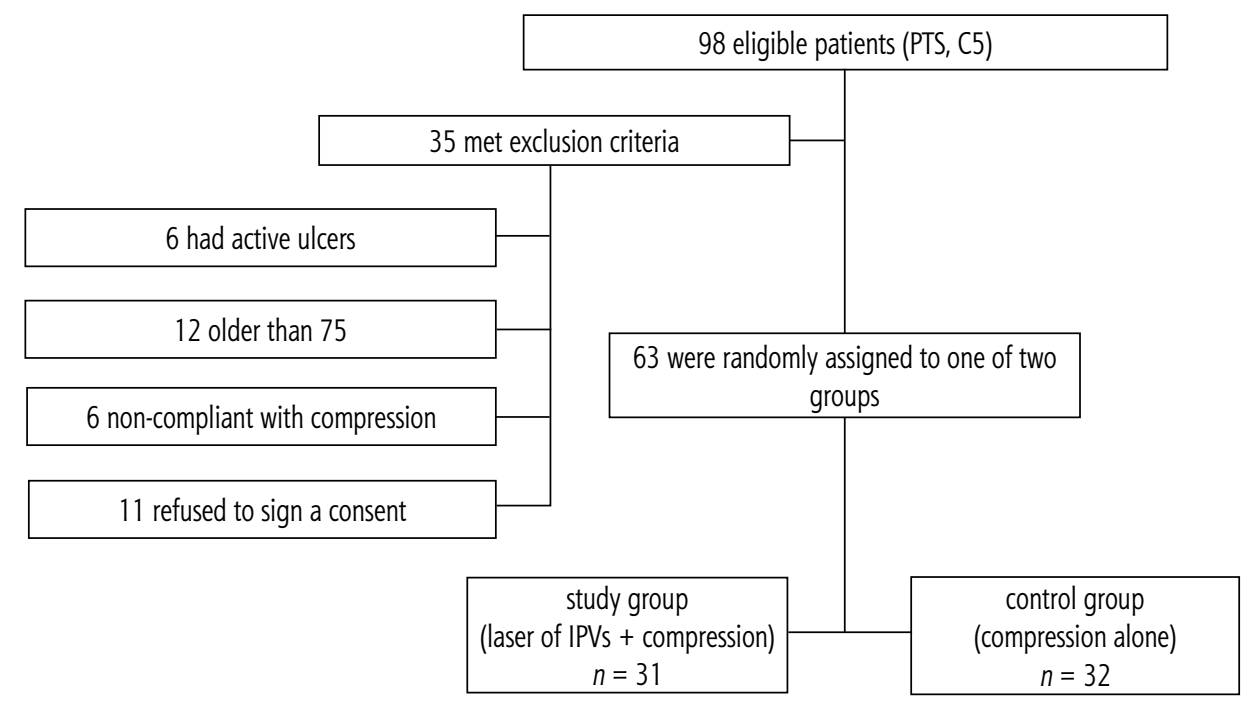

Fig. 1. Flow of patients through the study 
Table 1. Baseline characteristics of patients

\begin{tabular}{lccc}
\hline & $\begin{array}{c}\text { Study group } \\
\text { (endovenous laser of IPVs + compression) } \\
(\boldsymbol{n}=31)\end{array}$ & $\begin{array}{c}\text { Control group } \\
\text { (compression) } \\
(\boldsymbol{n}=32)\end{array}$ & $p$ \\
\hline Female & $12(39 \%)$ & $10(31 \%)$ & 0.603 \\
\hline Age & 50 & 53 & 0.812 \\
(mean, range) & $(33-72)$ & $(34-74)$ & 0.412 \\
\hline $\begin{array}{l}\text { VCSS } \\
\text { (mean, min.-max.) }\end{array}$ & 13 & 13 & 0.719 \\
\hline $\begin{array}{l}\text { Duration of PTS, years } \\
\text { (mean, min.-max.) }\end{array}$ & $(10-18)$ & $(9-16)$ & - \\
\hline Incompetent PV's in the area of healed & 11.5 & 11.2 & $(2-39)$ \\
ulcer & $(3-27)$ & 81 & 0.087 \\
\hline PVs $>$ 3.5 mm & 91 & $54(62 \%)$ & 0.787 \\
\hline $\begin{array}{l}\text { Diameter of PV's, cm } \\
\text { (mean, min.-max.) }\end{array}$ & $48(53 \%)$ & 0.41 & $(0.2-0.86)$ \\
\hline
\end{tabular}

muscle contraction or distal compression manoeuvres. If the flow was bi-directional, with duration of reflux longer than $0.5 \mathrm{~s}$, the vein was considered incompetent. All sonographic examinations before and after procedures were performed by two phlebologists with expertise in sonographic assessment of the venous system.

\section{Endpoints of the study}

The primary endpoint of the study was the rate of ulcer recurrence (at least one episode of ulcer recurrence) within one year of follow-up. In addition, we evaluated the technical success of laser ablation of perforators (early: 3-5 days after the procedure; and late: 1 year after ablation).

\section{Procedure}

Laser ablation of incompetent calf perforators was performed on an inpatient basis, under intravenous or epidural anaesthesia. Due to health service regulations we could not perform the procedures on an outpatient basis. We used a $940 \mathrm{~nm}$ laser system (Medilas D SkinPulse, Dornier Med Tech, Germany). We performed laser ablation of all incompetent perforators in the area of the healed ulcer, regardless of their calibre. Perforating veins, under the sonographic control, were punctured with a $21 \mathrm{G}$ needle. After locating the tip of the needle in the perforator's lumen, which was confirmed with both duplex-imaging and blood flowing out of the needle, we inserted the laser fibre into the needle. The tip of laser was positioned in the lumen of the vein. We used the pulse mode regime, with $15 \mathrm{~W}$ power and impulse duration of $1 \mathrm{~s}$. The number of impulses varied from 5 to 45 , depending on the diameter of the perforating vein. We applied at least 5 impulses in veins smaller than $0.3 \mathrm{~cm}$ in diam- eter, at least 20 impulses in $0.4-0.6 \mathrm{~cm}$ diameter veins, and 25-40 impulses if the diameter of the vein was more than $0.6 \mathrm{~cm}$. Total energy applied varied from 75 to $600 \mathrm{~J}$. Mean energy was $155 \mathrm{~J}$ and mean linear endovenous energy density was $186 \mathrm{~J} / \mathrm{cm}$.

\section{Follow-up}

The technical success of laser ablation was assessed by duplex ultrasound 3-5 days and 1 year after the procedure. If the perforating vein was non-compressible and presented with no flow on colour-Doppler, we considered such a perforator as completely occluded.

After 1 year patients from both groups underwent clinical examination, the VCSS was evaluated and all cases of ulcer recurrence during follow-up were recorded.

\section{Statistical analysis}

Data were collected using MS Excel and analysed with open access online statistics calculators. Continuous variables, such as the age and diameter of the perforating vein, were assessed with the two-tailed $t$ test. Ordinal data, such as the VCSS, were assessed with the Mann-Whitney test. Proportions were compared by the Fisher exact test. The significance of the $p$ value was set at $<0.05$.

\section{RESULTS}

\section{Immediate technical success, intra- and postoperative complications}

Despite trophic changes of the skin, there were no technical problems to manage incompetent perforators with the endovenous laser. Puncture of all perforators intended to ablate was successful, irrespective of their 
Table 2. The results of the study

\begin{tabular}{lccc}
\hline & Study group & Control group & $p$ \\
\hline Complications & none & NA & - \\
\hline Closed PVs at day 5 & $70 / 91(77 \%)$ & NA & - \\
\hline Closed PVs at 1 year & $17 / 70(24 \%)$ & NA & - \\
\hline Ulcer's recurrence & $10 / 31(32 \%)$ & $11 / 32(34 \%)$ & 1.000 \\
\hline VCSS & 13 & 13 & 0.412 \\
(mean, range) & $(10-18)$ & $(9-16)$ & \\
\hline
\end{tabular}

location and diameter. There were no intraoperative and postoperative complications, such as skin burns, paresthesiae, inflammatory reaction in the area of laser ablation, deep or superficial venous thrombosis (Table 2).

Three to five days after endovenous laser ablation we performed sonographic examination of all treated legs. Out of 91 previously incompetent perforators, 70 of them were completely occluded (non-compressible and no blood flow was detected during colour-Doppler sonography). Thus, the early success rate was $76.9 \%$ (Table 2 ).

\section{Results after 1 year}

No patients were lost for follow-up after 1 year. Venous ulcers recurred in 10 patients in the study group (32\%) and in 11 patients in the control group (34\%) (the difference was statistically insignificant; $p=0.859$ ). Thus, in terms of ulcer recurrence, the results of laser ablation of incompetent perforators with subsequent compression in C5 post-thrombotic patients did not differ from the treatment comprising compression alone. Control sonographic examination revealed that 1 year after laser ablation only 17 perforators were still occluded. Therefore, the technical success after 1 year was only $18.7 \%$. We compared the recurrence rate in 12 patients with at least one occluded perforator at 1 year with the patients in whom all perforators reopened, and also with the patients from the control group. There were 4 ulcer recurrences $(33 \%)$ in the group of 12 patients with at least one occluded perforator, 6 recurrences (32\%) in the group of 19 patients with all perforators reopened and 11 recurrences (34\%) in the control group (32 patients). There were no statistically significant differences between these groups. Mean VCSS did not change after one year, either in the study or in the control group (Table 2).

\section{DISCUSSION}

Although a lot of studies on endovenous laser treatment for CVD have been published, nearly all of them discussed an ablation of the great or short saphenous veins and very little information can be found on technical or clinical efficacy of endovenous thermal ablation of incompetent perforators, especially in the settings of
PTS. Proebstle et al. reported occlusion of 66 out of 67 perforators one week after the procedure [14]. Hissink et al. ablated 58 incompetent perforators in 33 lower limbs in 18 patients presenting with the $\mathrm{C} 4-\mathrm{C} 5$ class and documented $78 \%$ occlusion rate after 3 months [15]. Dumantepe et al. successfully obliterated 20 out of 23 (86.9\%) incompetent perforators [16]. Shi et al. reported 100\% technical success in 156 limbs [17]. Zerweck et al. performed laser ablation of 69 perforators with the occlusion rate after 1 month at a level of $95.6 \%$ [18]. We achieved significantly different results from those published. Our early occlusion rate was $77 \%$ and after 1 year only $19 \%$ of incompetent perforators remained occluded.

The success rate of the laser ablation could potentially be associated with total energy used to occlude incompetent veins. In the study of Proebstle et al. this energy amounted to 103-443 J with the use of $1320 \mathrm{~nm}$ laser, and 90-625 J with the use of $940 \mathrm{~nm}$ laser. Hissink et al. who used an $810 \mathrm{~nm}$ system, applied 87-325 J of energy (187 J in average). Dumantepe et al. applied 105-236 J (average: $174 \mathrm{~J}$ ) with the use of $1470 \mathrm{~nm}$ laser. In the study of Zerweck et al., who utilized a $1470 \mathrm{~nm}$ laser, mean energy density was $132 \mathrm{~J} / \mathrm{cm}$. The algorithm recommended by the guidelines of the American Venous Forum [19] suggests delivering the energy at three levels: just under the fascia, at the level of fascia and above it. At each side laser energy should be delivered twice, in the pulse mode, with a pulse duration of $4 \mathrm{~s}$ and power of $15 \mathrm{~W}$. Thus, the energy should be $120 \mathrm{~J}$ for each level and total energy delivered to occlude the perforating vein should be $360 \mathrm{~J}$. In our study we did not use less than $75 \mathrm{~J}$ in $0.2-0.3 \mathrm{~cm}$ diameter veins, at least $300 \mathrm{~J}$ in $0.4-0.6 \mathrm{~cm}$ diameter veins, and 325-600 $\mathrm{J}$ to occlude veins wider than $0.6 \mathrm{~cm}$ in diameter. Mean energy was $155 \mathrm{~J}$ and mean energy density was $186 \mathrm{~J} / \mathrm{cm}$. Therefore, we used the same or higher energy if compared with previously published data. So, we do not think that the difference between our results and data coming from the literature could be explained by inadequate energy applied. However, all of the above-cited studies regarded CVD patients, who were not distinguished into the individuals with primary venous disease and patients with PTS. Some studies comprised only patients with primary disease [17]. In general, it is unclear how many PTS patients were evaluated in these 
studies (only Hissink et al. [15] described laser ablation of incompetent perforators in the patients with trophic changes of the skin). Also, it is possible that successful ablation of perforators in PTS patients is much more difficult than in patients with primary varicose veins. In the settings of trophic changes of the skin, such as lipodermatosclerosis accompanied by severe microcirculatory impairment, it is possible that permanent occlusion of a perforator located in such a tissue is not very likely.

It should also be acknowledged that occlusion of perforators does not guarantee clinical success. In the case of trophic changes of the skin, clinical efficacy should be determined not only in terms of healing of an ulcer, but also taking into account ulcer recurrence. In our patient series, ulcers recurred with the same frequency in patients who had all perforators reopened as in patients with at least one successfully occluded perforator. In addition, recurrence of venous ulcers in our study was comparable to the recurrence after subfascial endoscopic dissection of perforators (SEPS). Recurrence of venous ulcers after the later procedure has been reported at a level of $16-46 \%$ [20]. So, it is possible that in PTS patients an interruption of incompetent perforators aimed at protection of patients from ulcer recurrence is of limited clinical value, irrespective of the method used to occlude these veins.

There are some limitations of our study. We used the $\mathrm{H}$-laser with an "old" bare fibre and the operations were not performed under local anaesthesia. Still, in our opinion it should not change significantly final results. Also, the number of assessed patients was rather small. In order to get $80 \%$ statistical power with the same main clinical outcomes, we should have recruited about 350 patients, which, given the relative rarity of $\mathrm{C} 5-\mathrm{C} 6$ patients with associated PTS, would be extremely difficult if not impossible to conduct by a single centre (or even single country).

According to our data, endovenous laser ablation of incompetent perforating veins does not reduce the recurrence of venous ulcers in patients with PTS and does not decrease severity of CVD measured with the VCSS. The technical success of endovenous laser ablation of perforators in PTS patients is low and the majority of incompetent perorating veins reopen within a year after the treatment. Yet, taking into account limitations of our study, we cannot conclude that this intervention is completely useless. Perhaps, an increased amount of energy delivered would result in a higher technical success and better clinical outcomes. More data are needed to determine an actual clinical value of thermal ablation of incompetent perforators in PTS patients.

\section{References}

1. Jawien A., Grzela T., Ochwat A. Prevalence of chronic venous insufficiency in men and women in Poland: multicentre cross-sectional study in 40,095 patients. Phlebology 2003; 18 : 110-122.

2. Oger E. Incidence of venous thromboembolism: a community-based study in Western France. Thromb Haemost 2000; 83: 657-660.

3. Nordström M., Lindblad B., Bergqvist D., Kjellström T. A prospective study of the incidence of deep-vein thrombosis within a defined urban population. J Intern Med 1992; 232: 155-160.

4. Prandoni P., Villalta S., Bagatella P., Rossi L., Marchiori A., Piccioli A., Bernardi E., Girolmi B., Simioni P., Girolami A. The clinical course of deep-vein thrombosis. Prospective long-term follow-up of 528 symptomatic patients. Haematologica 1997; 82: 423-428.

5. Kahn S.R., Hirsch A., Shrier I. Effect of postthrombotic syndrome on health-related quality of life after deep venous thrombosis. Arch Intern Med 2002; 162: 1144-1148.

6. Kachroo S., Boyd D., Bookhart B.K., LaMori J., Schein J.R., Rosenberg D.J., Reynolds M.W. Quality of life and economic costs associated with postthrombotic syndrome. Am J Health Syst Pharm 2012; 69: 567-572.

7. Monk B.E., Sarkany I. Outcome of treatment of venous stasis ulcers. Clin Exp Dermatol 1982; 7: 397-400.

8. Moffatt C.J., Dorman M.C. Recurrence of leg ulcers within a community ulcer service. J Wound Care 1995; 4: 57-61.

9. Vowden K.R., Barker A., Vowden P. Leg ulcer management in a nurse-led, hospital-based clinic. J Wound Care 1997; 6: 233236.

10. Milic D.J., Zivic S.S., Bogdanovic D.C., Perisic Z.D., Milosevic Z.D., Jankovic R.J., Visnjic A.M., Jovanovic B.M.. A randomized trial of the Tubulcus multilayer bandaging system in the treatment of extensive venous ulcers. J Vasc Surg 2007; 46: 750-755.

11. Marrocco C.J., Atkins M.D., Bohannon W.T., Warren T.R., Buckley C.J., Bush R.L. Endovenous ablation for the treatment of chronic venous insufficiency and venous ulcerations. World J Surg 2010; 34: 2299-2304.

12. Teo T.K., Tay K.H., Lin S.E., Tan S.G., Lo R.H., Taneja M., Irani F.G., Sebastien M.G., Lim K.H., Tan B.S. Endovenous laser therapy in the treatment of lower-limb venous ulcers. J Vasc Interv Radiol 2010; 21: 657-662.

13. Gloviczki P., Bergan J.J., Rhodes J.M., Canton L.G., Harmsen S., Ilstrup D.M. Mid-term results of endoscopic perforator vein interruption for chronic venous insufficiency: lessons learned from the North American subfascial endoscopic perforator surgery registry. The North American Study Group. J Vasc Surg 1999; 29: 489-502.

14. Proebstle T.M., Herdemann S. Early results and feasibility of incompetent perforator vein ablation by endovenous laser treatment. Derm Surg 2007; 33: 162-168.

15. Hissink R.J., Bruins R.M., Erkens R., Castellanos Nuijts M.L., van den Berg M. Innovative treatments in chronic venous insufficiency: endovenous laser ablation of perforating veins: a prospective short-term analysis of 58 cases. Eur J Vasc Endovasc Surg 2010; 40: 403-406.

16. Dumantepe M., Tarhan A., Yurdacul I., Ozler A. Endovenous laser ablation of incompetent perforating veins with $1470 \mathrm{~nm}$, 400 mum radial fiber. Photomed Laser Surg 2012; 30: 672-677.

17. Shi H., Liu X., Lu M., Lu X., Jiang M., Yin M. The Effect of Endovenous Laser Ablation of Incompetent Perforating Veins and the Great Saphenous Vein in Patients with Primary Venous Disease. Eur J Vasc Endovasc Surg 2015; 49: 574-580. 
18. Zerweck C., von Hodenberg E., Knittel M., Zeller T., Schwarz T. Endovenous laser ablation of varicose perforating veins with the 1470-nm diode laser using the radial fibre slim. Phlebology 2014; 29: 30-36.

19. Elias S. Percutaneous ablation of perforating veins. In: GloviczkiP. (ed.). Handbook of venous disorders: guidelines of the American Venous Forum. 3rd ed. Hodder Arnold; London 2009; 536544.

20. Kalra M., Gloviczki P., Noel A.A., Rooke T.W., Lewis B.D., Jenkins G.D., et al. Subfascial endoscopic perforator vein surgery in patients with post-thrombotic venous insufficiency - is it justified? Vasc Endovascular Surg 2002; 36: 41-50. 